\title{
Experimental Study of Buffer Gas Flow Rate Effect on Output Power of a Copper Vapor Laser
}

\author{
Saeid Behrouzinia ${ }^{*}$, Kamran Khorasani ${ }^{1}$, Saeid Marjani' ${ }^{2}$, Masoud Sabaghi ${ }^{1}$, \\ Mohammad Ebrahim Aeinehvand ${ }^{3}$, Sadegh Mohammadpour ${ }^{3}$ \\ ${ }^{1}$ Laser and Optics Research School, Nuclear Science and Technology Research School, Atomic Energy \\ Organization of Iran, Tehran, Iran \\ ${ }^{2}$ Department of Electrical Engineering, Ferdowsi University of Mashhad, Mashhad, Iran \\ ${ }^{3}$ Research and Sciences branch, Islamic Azad University, Tehran, Iran \\ Email: "sbehrouzi@aeoi.org.ir
}

Received 15 July 2015; accepted 14 February 2016; published 17 February 2016

Copyright (C) 2016 by authors and Scientific Research Publishing Inc.

This work is licensed under the Creative Commons Attribution International License (CC BY).

http://creativecommons.org/licenses/by/4.0/

c) (i) Open Access

\section{Abstract}

A copper vapor laser with active medium length of $60 \mathrm{~cm}$ and bore of $16 \mathrm{~mm}$ has been operated and optimized using different buffer gases to investigate the effect of the gas flow rates on the output power. It is found that there is a special optimum gas flow rate associated with the type of buffer gas.

\section{Keywords}

\section{Copper Vapor Laser, Gas Flow Rate, Output Power}

\section{Introduction}

The lasers are sources of light with very special properties that emit light based on the stimulated emission of electromagnetic radiation. There is a great variety of laser applications but most of them are used only for specialised research [1]-[26]. The copper vapor lasers (CVLs) are one of the efficient sources of coherent light in visible region at $510.6 \mathrm{~nm}$ and $578.2 \mathrm{~nm}$ with high average output powers [27]. CVLs have wide applications in the research, medicine and industry and have been used extensively in high speed imaging, micro-machining, non-linear frequency conversion to the ultraviolet and photodynamic therapy. Moreover, they have considered as a powerful pumping source for dye lasers [27]-[31], particularly by means of a master oscillator-power am"Corresponding author. 
plifier array, in order to satisfy higher output powers and beam quality simultaneously [32] [33]. The output power of CVL involved many factors and the type of buffer gas only had some influences on it. It could be finding that the fluctuations of the output power of CVL based on the type of buffer gas are not very slight. The buffer gas is employed in CVL tube to increase the output power and improve the laser performance [34] [35]. It provides a discharge medium before reaching the discharge tube to the temperature required for copper vapor production. The buffer gas is necessary to produce the population inversion mechanism via energy transfer of the gas, ions or electrons to the metal atoms. It shapes the electron-energy-distribution function through elastic collisions. It also protects the windows against contamination and transfers heat from tube axis to the walls. Addition of a buffer gas allows the impedance of the discharge tube to increase, thus leads to improving impedance matching by the excitation circuit [29]. In CVLs, the non-reactive inert gases with high excitation and ionization energies have been used as the buffer gases to minimize the influence of inelastic electron collisions on the electron energy distribution function. Among of the $\mathrm{He}, \mathrm{Ne}, \mathrm{Ar}, \mathrm{Kr}, \mathrm{Xe}$ and their mixtures gases, neon enables laser oscillation at the highest gas pressure and provides the highest output power [36]. The next best buffer gas to use is He, which gives longer and lower discharge current pulses [28]. Weak oscillations are also obtained with $\mathrm{N}_{2}$ [37], $\mathrm{H}_{2}$ [38], and $\mathrm{CO}_{2}$ buffer gases [39]. Adding of $\mathrm{H}_{2}$ to the Ne buffer gas in CVL greatly enhances its performance [38] [40] [41]. In our previous work, a CVL and a gold vapor laser were operated using air as a buffer gas to compare output power and the stability of the laser by the air and other gases [42]. Also, we used a pair of CVL in the oscillator-amplifier configuration for investigating the small-signal gain and the intensity saturation as the amplifying parameters, versus the pressure of various types of buffer gases. It is shown that the smallsignal gain increases and the intensity saturation decreases with increase in the air pressure. Moreover, the values of these parameters are different for various gases used in the amplifier media [43]. The amplifying parameters, and then output power, and interval of operational pressure of CVL have been strongly affected by buffer gas. In this work, a CVL has been operated by using some different buffer gases such as the He, Ne and air. Some similar works have been studied generally, which investigated the effects of buffer gas pressure and some additive gases on CVL output characteristics. In this work, the behavior of the laser output power versus gas flow rate of these gases has been investigated to obtain the optimum conditions. It is shown that the gas flow rate is depending upon the type of buffer gas. However, abundance of the air and reduction of the system volume due to eliminating the gas handling as well as the economically benefits are the advantages of employing air as a buffer gas in CVL operation in some researches or educational cases. The rest of this paper is as follows. Section 2 describes the experimental setup. The obtained results and discussion are presented in Section 3. Finally, we conclude in Section 4.

\section{Experimental Setup}

The discharge tube of CVL has been made of Alumina with inner diameter of $16 \mathrm{~mm}$ and active medium length of $60 \mathrm{~cm}$, surrounded by a fibrous alumina insulation covering with a Pyrex tube and an external stainless steel jacket. Two cylindrical electrodes made of molybdenum are employed for discharging. A couple of flat-flat resonator with reflectivity of $98 \%$ and $4 \%$ are considered as the back and front mirrors, respectively. The laser tube is coupled to the standard driven circuit as illustrated in Figure 1. The gas on the tube is excited by the discharge of a 1.65-nF main capacitor $\left(\mathrm{C}_{\mathrm{s}}\right)$ through the TGI1-1000/25 Thyratron, which is cooled by air. A 0.68$\mathrm{nF}$ peaking capacitor $\left(\mathrm{C}_{\mathrm{p}}\right)$ is connected between the tube electrodes as well as the $0.15 \mathrm{mH}$ inductance $\left(\mathrm{L}_{2}\right)$.

The laser output is measured by a Molectron ${ }^{\mathrm{TM}}$ PM500D power meter. Precision needle valve is used to control the gas flow rate and a gauge is used to pressure measuring of buffer gas in the tube.

\section{Results and Discussion}

In our work, three gases, $\mathrm{Ne}, \mathrm{He}$, and air have been used as buffer gas individually, and the output powers are measured under same conditions, that is, the electrical input power is kept at $1.7 \mathrm{~kW}$ and the pulse repetition frequency is fixed at $20 \mathrm{kHz}$. The output power of 6,4 and $1.9 \mathrm{~W}$ are obtained with $\mathrm{Ne}$, He and air gases with the optimum pressure of 30, 20 and 3.8 torr, respectively. The laser output powers with these gases are measured versus gas flow rates, individually. The results are shown in Figure 2. It is finding that the laser output power increased by the gas flow rate, first, and after reaching to a maximum value, it reduces at higher flow rates. The maximum output power is achieved by using of $\mathrm{Ne}$, and minimum one is obtained by air as buffer gas. The optimum values of gas flow rate of $\mathrm{He}$ and $\mathrm{Ne}$ are approximately 15 and $12 \mathrm{Lit} / \mathrm{min}$, respectively, but this one is 23 


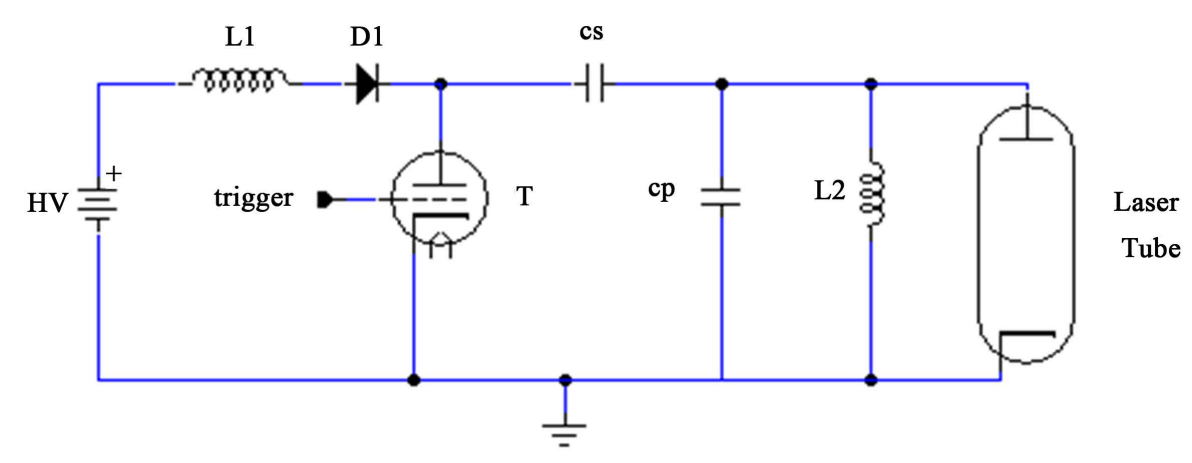

Figure 1. Schematic layout of standard driven circuit of CVL.

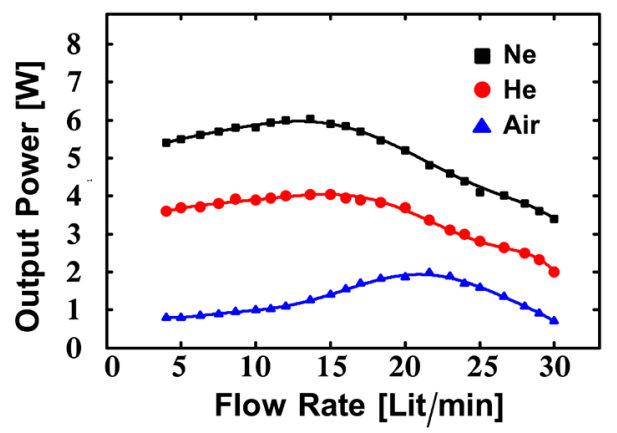

Figure 2. The laser output power versus different buffer gases flow rate.

Lit/min for air, which gives the maximum output powers. It is shown that the optimum value of air flow rate is more than that of other gases, due to existence of small percent of hydrogen in air which improve the output power of laser.

At low flow rate, the output power would be increased. The flow rate is maintained to permit the excited metal atoms to emit laser radiation by stimulated emission to a lower laser level in the discharge region and to remove the lower laser level atoms. Moreover, the impurities at a low flow rate would be removed. There is an optimum flow rate, which the maximum output power is obtained. By increasing of flow rate more than its optimal value, the output power is decreased, because of at higher flow rates, the electron energy function distribution and temperature rise across the length of the tube are altered, which affected on population inversion. It could be finding that the performance of CVL has strongly dependent on the type of buffer gas.

\section{Conclusion}

The type of buffer gas has been strongly influencing the output power of CVL. The results show that the gas flow rate is depending upon the type of gas. The optimum of air flow rate is higher than that of other conventional gases, due to the existence of the small percent of hydrogen in the air, which improves the output power of laser.

\section{References}

[1] Faez, R., Marjani, A. and Marjani, S. (2011) Design and Simulation of a High Power Single Mode $1550 \mathrm{~nm}$ InGaAsP VCSELs. IEICE Electronics Express, 8, 1096-1101. http://dx.doi.org/10.1587/elex.8.1096

[2] Marjani, S., Faez, S. and Marjani, H. (2011) An Impact of the Hole Etching Depth within a Photonic Crystal VCSEL on Its Heat Sources. Australian Journal of Basic and Applied Sciences, 5, 766-770.

[3] Marjani, S., Faez, R. and Marjan, A. (2011) Design and Modeling of a High Single Mode Power Long Wavelength InGaAsP Photonic Crystal VCSEL. Australian Journal of Basic and Applied Sciences, 5, 1064-1069.

[4] Marjani, A., Marjani, S. and Shirazian, S. (2011) Numerical Simulation of Silicon Carbide Polymers (6H-SiC \& 3C-SiC) as the Active Area for $0.83 \mu \mathrm{m}$ Wavelength Semiconductor Laser. The 14th Iranian Physical Chemistry Conference, University of Tehran, Kish, Iran, 25-28 February 2011, 876-878. 
[5] Marjani, S., Faez, R. and Marjani, H. (2011) Analysis and Design of Semiconductor Laser with Silicon Carbide Polymers (6H-SiC and 3C-SiC). Australian Journal of Basic and Applied Sciences, 5, 1060-1063.

[6] Marjani, S., Rahnama, M. and Marjani, H. (2011) Numerical Optimization of Single-Mode InGaAsP Vertical-Cavity Surface-Emitting Lasers. Australian Journal of Basic and Applied Sciences, 5, 1207-1211.

[7] Marjani, S. and Marjani, H. (2011) Effects of Lattice Temperature on the Various Elements of Heat Sources in a Long Wavelength InGaAsP Photonic Crystal VCSEL. Australian Journal of Basic and Applied Sciences, 5, 1257-1261.

[8] Marjani, S. and Marjani, H. (2011) Analysis of Lattice Temperature Effects on a Long Wavelength InGaAsP Photonic Crystal VCSEL. Australian Journal of Basic and Applied Sciences, 5, 1374-1378.

[9] Marjani, S. and Marjani, H. (2012) Optimization of a Long Wavelength Vertical-Cavity Surface-Emitting Lasers by Employing Photonic Crystal. Asian Journal of Chemistry, 24, 3174-3176.

[10] Marjani, S. and Marjani, H. (2012) Self-Heating Effects in a Silicon Carbide Polymers (6H-SiC and 3C-SiC) Semiconductor Laser. Asian Journal of Chemistry, 24, 3145-3147.

[11] Marjani, S. and Marjani, H. (2012) Effects of Hole Etching Depth in a Long Wavelength InGaAsP Photonic Crystal Vertical Cavity Surface Emitting Laser. Asian Journal of Chemistry, 24, 3194-3196.

[12] Marjani, S. and Marjani, H. (2012) Effects of Lattice Temperature on the Various Elements of Heat Sources in Silicon Carbide Polymers (6H-SiC and 3C-SiC) Semiconductor Laser. Asian Journal of Chemistry, 24, 3123-3125.

[13] Marjani, S., Faez, R. and Marjani, H. (2012) Analysis of the Various Elements of Heat Sources in Silicon Carbide Polymers (6H-SiC and 3C-SiC) Semiconductor Laser. Asian Journal of Chemistry, 24, 2333-2335.

[14] Marjani, S., Faez, R. and Marjani, H. (2012) Design and Modeling of a Semiconductor Laser by Employing Silicon Carbide Polymers (6H-SiC, 3C-SiC and 4H-SiC). Asian Journal of Chemistry, 24, 2177-2179.

[15] Marjani, S., Faez, R. and Hosseini, S.E. (2013) Analysis of Lattice Temperature Effects on a GaInP/6H-SiC Strained Quantum-Well Lasers. Asian Journal of Chemistry, 25, 4715-4717. http://dx.doi.org/10.14233/ajchem.2013.13072

[16] Madadi, R., Marjani, S. and Faez, R. (2013) Silicon Carbide Polymers (6H-SiC, 3C-SiC and 4H-SiC) Semiconductor Laser: Influence of Self-Heating. Proceedings of the 3rd Iranian Conference on Optics and Laser Engineering (ICOLE), Isfahan, 9-10 October 2013, 1069-1072.

[17] Marjani, S. (2013) Various Elements of Heat Sources within an Optimized Photonic Crystal Vertical Cavity Surface Emitting Laser: Influence of Hole Etching Depth. Asian Journal of Chemistry, 25, 4153-4156. http://dx.doi.org/10.14233/ajchem.2013.13281

[18] Marjani, S. (2013) Optimization of an InGaAsP Vertical-Cavity Surface-Emitting Diode Lasers for High-Power Single-Mode Operation in 1550 nm Optical-Fibre Communication Systems. Asian Journal of Chemistry, 25, 4150-4152. http://dx.doi.org/10.14233/ajchem.2013.13186

[19] Marjani, S., Faez, R. and Hosseini, S.E. (2013) Threshold Characteristics Analysis of InP-Based PhC VCSEL with Buried Tunnel Junction. Proceedings of the 21st Iranian Conference on Electrical Engineering (ICEE), Mashhad, 14-16 May 2013, 1-4. http://dx.doi.org/10.1109/iraniancee.2013.6599783

[20] Majdabadi, A., Marjani, S. and Sabaghi, M. (2014) Threshold Characteristics Enhancement of a Single Mode $1.55 \mu \mathrm{m}$ InGaAsP Photonic Crystal VCSEL for Optical Communication Systems. Optics and Photonics Journal, 4, 296-303. http://dx.doi.org/10.4236/opj.2014.410029

[21] Naeemi, M.A., Marjani, S. and Peiravi, A. (2014) Time to Failure Analysis of Single Mode Long-Wavelength InGaAsP Vertical-Cavity Surface-Emitting Lasers. Proceedings of the 22st Iranian Conference on Electrical Engineering (ICEE), Tehran, 20-22 May 2014, 43-47. http://dx.doi.org/10.1109/iraniancee.2014.6999500

[22] Khosroabadi, S., Keshmiri, S.H. and Marjani, S. (2014) Design of a High Efficiency CdS/CdTe Solar Cell with Optimized Step Doping, Film Thickness, and Carrier Lifetime of the Absorption Layer. Journal of the European Optical Society, 9, 14052-1-14052-6. http://dx.doi.org/10.2971/jeos.2014.14052

[23] Sabaghi, M., Majdabadi, A., Marjani, S. and Khosroabadi, S. (2015) Optimization of High-Efficiency CdS/CdTe Thin Film Solar Cell Using Step Doping Grading and Thickness of the Absorption Layer. Oriental Journal of Chemistry, 31, 891-896. http://dx.doi.org/10.13005/ojc/310232

[24] Sabaghi, M., Majdabadi, A., Khosroabadi, S. and Marjani, S. (2015) A Novel Ultrathin CdS/CdTe Solar Cell with Conversion Efficiency of 31.2\% for Nano-Area Application. Proceedings of the Progress in Electromagnetics Research Symposium (PIERS), Prague, 6-9 July 2015, 1152-1155.

[25] Sabaghi, M., Majdabadi, A. and Oskui, H.S. (2007) Intelligent Controlling on Diode Laser Wavelength Based Embedded System. Proceedings of the International Universities Power Engineering Conference (UPEC), Brighton, 4-6 September 2007, 387-391. http://dx.doi.org/10.1109/UPEC.2007.4468978

[26] Rafighi, F., Behrouzinia, S., Khorasani, K., Sabaghi, M. and Marjani, S. (2016) The Electrical Parameters Modeling and Experimentation of Copper Vapor Laser. Circuits and Systems, 7, 23-28. http://dx.doi.org/10.4236/cs.2016.71003 
[27] Withford, M.J., Brown, D.J.W., Mildren, R.P., Carman, R.J., Marshall, G.D. and Piper, J.A. (2004) Advances in Copper Laser Technology: Kinetic Enhancement. Progress in Quantum Electronics, 28, 165-196. http://dx.doi.org/10.1016/j.pquantelec.2003.12.001

[28] Withford, M.J., Brown, D.J.W., Coutts, D.W. and Piper, J.A. (1995) Copper Vapor Laser Unstable Resonator Oscillator and Oscillator-Amplifier Characteristics. IEEE Journal of Quantum Electronics, 31, 898-902. http://dx.doi.org/10.1109/3.375935

[29] Little, C.E. (1999) Metal Vapor Lasers. John Wiley \& Sons, Chichester.

[30] Huang, Z.G., Namba, K. and Shimizu, F. (1986) Influence of Molecular Gases on the Output Characteristics of a Copper Vapor Laser. Japanese Journal of Applied Physics, 25, 1677-1679. http://dx.doi.org/10.1143/JJAP.25.1677

[31] Grant, B. (1997) Lasers Improve Uranium Enrichment. Photonics Spectra. http://www.photonics.com/Article.aspx?AID=1201

[32] Behrouzinia, S., Sadighi, R. and Parvin, P. (2003) Pressure Dependence of Small-Signal Gain and Saturation Intensity of a Copper Vapor Laser. Applied Optics, 42, 1013-1018. http://dx.doi.org/10.1364/AO.42.001013

[33] Behrouzinia, S., Sadighi, R. and Parvin, P. (2004) Temperature Dependence of the Amplifying Parameters of a Copper Vapor Laser. Laser Physics, 14, 1050-1053.

[34] Zand, M. and Khorasani, K. (2014) Design and Construction of a Three-Color Gold-Copper-Vapor Laser and the Output-Power Dependence on the Frequency and Buffer-Gas Pressure. Journal of Russian Laser Research, 35, $268-272$. http://dx.doi.org/10.1007/s10946-014-9422-7

[35] Behrouzinia, S., Khorasani, K. and Kazemi, H. (2013) Dependence of the Amplifying Parameters on Buffer Gases in Copper-Vapor Lasers. Journal of Russian Laser Research, 34, 103-108. http://dx.doi.org/10.1007/s10946-013-9329-8

[36] Lesnoi, M.A. (1984) Influence of Te Gas Mixture Composition and Cathode Material on the Output Power of Copper Vapor Laser. Soviet Journal of Quantum Electronics, 14, 142-148. http://dx.doi.org/10.1070/QE1984v014n01ABEH004664

[37] Ferrar, C.M. (1974) Buffer Gas Effects in a Rapidly Pulsed Copper Vapor Laser. IEEE Journal of Quantum Electronics, 10, 655-657. http://dx.doi.org/10.1109/JQE.1974.1068371

[38] Tiwari, G.N., Shukla, P.K., Mishra, R.K., Shrivastava, V.K., Khara, R. and Nakhe, S.V. (2015) Effect of Addition of Hydrogen to Neon Buffer Gas of Copper Bromide Vapor Laser on Its Spectral and Temporal Characteristics. Optics Communication, 338, 322-328. http://dx.doi.org/10.1016/j.optcom.2014.10.048

[39] Bokhan, P.A. and Solomonov, V.I. (1974) Mechanism of Laser Action in Copper Vapor. Soviet Journal of Quantum Electronics, 3, 481-486. http://dx.doi.org/10.1070/QE1974v003n06ABEH005640

[40] Withford, M.J., Brown, D.J.W. and Piper, J.A. (1996) Optimization of $\mathrm{H}_{2}$-Ne Buffer Gas Mixtures for Copper Vapor Laser. IEEE Journal of Quantum Electronics, 32, 1310-1315. http://dx.doi.org/10.1109/3.511543

[41] Hayashi, K., Iseki, Y., Szuki, S., Watanabe, I., Noda, E. and Morimiya, O. (1992) Improvement in the Output Characteristics of a Large-Bore Copper Vapor Laser by Hydrogen. Japanese Journal of Applied Physics, 31, 689-697. http://dx.doi.org/10.1143/JJAP.31.L1689

[42] Khorasani, K., Behrouzinia, S. and Salehinia, D. (2008) Air as a Buffer Gas in Metal-Vapor Lasers. Journal of Russian Laser Research, 29, 599-603. http://dx.doi.org/10.1007/s10946-008-9047-9

[43] Behrouzinia, S., Khorasani, K., Kazemi, H. and Mashayekhi, H. (2011) Frequency Dependence of Amplifying Parameters of a Copper Vapor Laser Using Air as a Buffer Gas. Journal of Russian Laser Research, 32, 212-218.

http://dx.doi.org/10.1007/s10946-011-9241-z 